\title{
Manajemen Asuhan Kebidanan Keluarga Berencana pada Ny"F" Akseptor KB Suntik DMPA dengan Peningkatan Berat Badan di Puskesmas Bara-Baraya Makassar Tanggal 07 Juli- 04 Agustus Tahun 2018
}

\author{
${ }^{1}$ Aisyah, ${ }^{2}$ Anieq, ${ }^{3}$ Rahma
}

\begin{abstract}
ABSTRAK
Pendahuluan Jumlah penduduk dari tahun ke tahun mengalami peningkatan yang relatif tinggi dan tidak seimbang. Hal ini mengakibatkan adanya tekanan yang berat dari berbagai bidang penyediaan pangan, sandang, perumahan, lapangan kerja, pendidikan, kesehatan dan lain-lain. Pemerintah melakukan penanganan dengan membuat program yaitu Keluarga Berencana $(\mathrm{KB})$ untuk mengendalikan laju pertumbuhan penduduk. KB suntik DMPA merupakan salah satu metode KB yang sangat efektif untuk mencegah terjadinya kehamilan.
\end{abstract}

Metode jenis penelitian ini adalah studi kasus dengan melaksanakan Manajemen Asuhan Kebidanan KB pada Ny. "F" Akseptor KB suntik DMPA Dengan Peningkatan Berat Badan Di Puskesmas Bara-baraya Makassar Tahun 2018 sesuai dengan 7 langkah Varney dan SOAP.

Hasil diagnosis pada Ny "F" ditegakkan dengan data subjektif, adanya keluhan mengalami peningkatan berat badan selama menjadi akseptor KB suntik DMPA dan data objektif didapatkan ibu pengguna KB suntik DMPA. Diketahui jika peningkatan berat badan yang dialami Ny "F" merupakan hal fisiologi bagi pengguna KB suntik DMPA dengan adanya konseling maka ibu tidak lagi merasa cemas dan khawatir dengan keadaannya.

Kesimpulan dari kasus tersebut yang dapat diambil adalah telah dilakukan pengumpulan data dasar, identifikasi diagnosa dan tindakan untuk Ny "F" sesuai dengan kasus akseptor KB suntik DMPA dengan peningkatan berat badan. Ibu mengerti jika peningkatan berat badan merupakan efek samping penggunaan DMPA. Hal lain yang penting adalah ibu memahami bahwa Islam menganjurkan upaya untuk meningkatkan kualitas keluarga termasuk melalui $\mathrm{KB}$
*UIN Alauddin Makassar

*aiffahds@gmail.com

*muthiah alkautsar@yahoo.com

*andisittirahma@yahoo.com

Kata kunci :

$K B$;

7 Langkah Varney;

Akseptor KB suntik DMPA

\section{PENDAHULUAN}

Peningkatan pertumbuhan penduduk yang sangat cepat merupakan salah satu karakteristik kependudukan di negara maju dan berkembang termasuk Indonesia. Hal ini dapat dilihat dari jumlah penduduk Indonesia yang berkembang sangat pesat dengan tingginya laju pertumbuhan penduduk. Indonesia merupakan negara keempat terbesar penduduknya di dunia dengan lebih dari 256 juta jiwa (Population Reference Bureau, 2015). 
Luas wilayah Indonesia mencapai $1.159 .578 .68 \mathrm{~km} 2$ dengan kepadatan penduduk sebesar 135,19 jiwa/km2 (Kemenkes RI, 2017).

Jumlah penduduk dari tahun ke tahun mengalami peningkatan yang relatif tinggi dan tidak seimbang. Hal ini mengakibatkan adanya tekanan yang berat dari berbagai bidang penyediaan pangan, sandang, perumahan, lapangan kerja, pendidikan, kesehatan dan lainlain. Untuk menangani hal tersebut maka pemerintah melakukan penanganan dengan membuat suatu program yaitu Keluarga Berencana (KB) untuk mengendalikan laju pertumbuhan penduduk (Maryam, 2014).

KB merupakan salah satu cara agar dapat menurunkan angka kematian ibu khususnya ibu dengan kondisi 4T yaitu Terlalu muda melahirkan (di bawah usia 20 tahun), Terlalu sering melahirkan, Terlalu dekat jarak melahirkan, dan Terlalu tua melahirkan (di atas usia 35 tahun). Salah satu tujuan dari program KB yaitu untuk meningkatkan kualitas keluarga agar dapat merasa aman, tentram, dan harapan masa depan yang lebih baik agar dapat mewujudkan kesejahteraan lahir dan kebahagiaan batin. Pelayanan KB mencakup beberapa informasi, pendidikan, dan upaya-upaya untuk keluarga agar dapat mengatur jarak usia antar anak, kapan akan mempunyai anak, berapa jumlah anak, dan kapan akan berhenti mempunyai anak (Kemenkes RI, 2017).

Ada beberapa macam metode kontrasepsi modern, ada yang mengandung hormon, dan tidak mengandung hormon. Untuk kontrasepsi hormonal, terdiri atas kontrasepsi oral/pil, injeksi/suntik, dan implant.Untuk metode kontrasepsi non hormonal terbagi atas kontrasepsi IUD/AKDR dan kontrasepsi mantap yaitu vasektomi dan tubektomi (Hartanto,2010:42).

Data peserta KB aktif menurut Profil kesehatan RI (2016), menunjukkan metode kontrasepsi yang terbanyak penggunaannya adalah suntikan, yakni sebanyak 17.414.144 (47,69\%), di susul KB pil sebesar 8.280.823 (22,81\%), di urutan ketiga adalah KB Implant sebesar 4.067.699 (11,20\%), di urutan ke empat adalah IUD sebanyak 3.852 .561 (10,61\%) Sedangkan metode kontrasepsi yang paling sedikit dipilih oleh peserta KB aktif adalah Metode Operasi Wanita (MOW) sebesar 1.285 .991 (3,54\%) kemudian Metode Operasi Pria (MOP), yaitu sebesar 233.935 (0,64\%) (Kemenkes RI, 2017).

Di Sulawesi Selatan peserta KB baru dan KB aktif pada tahun 2016 dengan jumalah pasangan usia subur (PUS) sebanyak 1.426.867. peserta KB baru sebesar 134.294(12,97\%) 
dan peserta KB aktif sebesar 1.024.418(72,30\%). Untuk metode kontrasepsi dengan pemakaian terbanyak adalah kontrasepsi suntikan sebesar 480.337(46,89\%), disusul kontrasepsi pil sebesar 292.426(28,55\%), diurutan ketiga yaitu kontrasepsi implant sebesar 139.944(13,66\%), diurutan keempat yaitu kontrasepsi IUD sebesar 46.154 (4,51\%), selanjutnya yaitu kontrasepsi kondom sebesar 42.318 (4,13\%) sedangkan metode kontrasepsi dengan pemakaian terendah adalah Metode Operasi Wanita (MOW) sebesar $21.124(2,06 \%)$ kemudian Metode Kontrasepsi Pria (MOP) sebesar 2.115 (0,21\%) (Kemenkes RI, 2017).

Data yang diperoleh dari Badan Pusat Statistik (BPS) Sulawesi selatan cakupan peserta KB aktif di makassar pada tahun 2015. Menujukkan metode kontrasepsi yang terbanyak di gunakan adalah suntikan sebanyak 53.200 orang, Pil sebanyak 30.288 orang, Implant sebanyak 14.709 orang, AKDR sebanyak 13.492 orang dan Kondom sebanyak 5.235 orang, Sedangkan metode yang paling sedikit dipilih yaitu, MOP sebanyak 614 orang, MOW sebanyak 4.354 orang (Badan Pusat Statistik, 2016).

Penggunaan alat kontrasepsi jenis suntikan masih menjadi pilihan untuk beberapa ibu.Di samping karena harganya yang relatif murah, kontrasepsi suntikan ini juga efektif, sederhana, aman, dan mudah di jangkau. Namun tidak dapat dipungkiriakan timbulnya konsekuensi lain dari penggunaan alat kontrasepsi suntik khususnya kontrasepsi suntik 3 bulan yang banyak dipakai. Keluhan yang paling sering dihadapi akseptor KB suntik adalah peningkatan berat badan.Alat kontrasepsi hormonal suntik DMPA merupakan satu-satunya kontrasepsi hormonal yang konsisten terkait dengan peningkatan berat badan (Sari, 2015).

Masalah berat badan merupakan masalah yang sangat banyak dan sering dipertanyakan oleh pasien jika mengalami kegemukan.Menjadi gemuk merupakan mimpi yang buruk bagi sebagian orang terutama bagi mereka yang sangat memperhatikan bentuk tubuh. Kegemukan juga akan menguras kepercayaan diri seseorang sehingga akan mempengaruhi karir orang yang bersangkutan. Peningkatan berat badan yang berlebih dapat menyebabkan penyakit yang serius berupa hipertensi, jantung koroner, diabetes mellitus, hiperkolestrolemia dan jika tidak dilakukan penanganan maka akan berdampak pada kematian (Purwanti dkk, 2012:25).

Pada wanita yang mengalami peningkatan berat badan yang berlebih akan beresiko berkembangnya penyakit kanker payudara dan rahim. Namun tidak semua akseptor KB akan mengalami kenaikan berat badan, karena efek dari obat tersebut tidak selalu sama pada 
masing- masing individu. Kenaikan berat badan yang berlebihan merupakan salah satu bentuk dari gizi berlebih yang secara umum diartikan sebagai peningkatan rasio lemak baik yang terlokalisir ataupun yang merata di seluruh tubuh (Purwati, 2005).

Rata-rata penambahan berat badan tidak terlalu besar, bervariasi antara kurang dari satu kilogram sampai dengan lima kilogram dalam tahun pertama pemakaian (Dewi dkk, 2016). Pada penelitian yang dilakukan oleh Berenson dan Rahman (2009) dapat disimpulkan bahwa selama 36 bulan wanita yang menggunakan kontrasepsi DMPA mengalami peningkatan berat sebesar $(5,1 \mathrm{~kg})$, lemak tubuh $(4,1 \mathrm{~kg})$, persen lemak tubuh $(+3,4 \%)$.

Peningkatan berat badan dapat dikaitkan pada hormon yang terkandung dalam kontrasepsi suntik DMPA yaitu hormon progesteron.Hormon progesteron ini dapat merangsang pusat pengendalian nafsu makan di hipotalamus sehingga menyebabkan terjadinya peningkatan nafsu makan (Pratiwi dkk, 2014).Tidak hanya mengakibatkan nafsu makan bertambah, hormon ini juga mempermudah perubahan karbohidrat dan gula menjadi lemak, sehingga lemak di bawah kulit bertambah (Firdayanti, 2012:108).

Berdasarkan data awal yang didapatkan di Puskesmas Barabaraya, didapatkan jumlah akseptor KB dari bulan September-desember 2017 sebanyak 156 akseptor. Metode kontrasepsi yang terbanyak digunakan adalah suntikan 3 bulan sebanyak 119 akesptor, Pil sebanyak 22 akseptor, Implant sebanyak 14 akseptor, dan IUD sebanyak 4 akseptor. Pada data tersebut tidak didapatkan keterangan mengenai adanya efek samping pada pengguna $\mathrm{KB}$ (Data register KB puskesmas Barabaraya Makassar, 2017)

\section{METODE PENELITIAN}

Jenis penelitian ini adalah studi kasus dengan pendekatan Manajemen Asuhan Kebidanan sesuai dengan 7 langkah Varney dan pendokumentasian dalam bentuk Penatalaksanaan Asuhan dilakukan dengan pemberian asuhan yang sesuai dengan standar operasional prosedur pada kasus yang diteliti yaitu aksptor KB denagn peningkatan berat badan serta melakukan upaya pencegahan Drop Out. 


\section{HASIL PENELITIAN}

Penelitian ini dilakukan di Puskesmas Bara-baraya Makassar mulai tanggal 07 Juli-04 Agustus 2018.Peneliti melakukan pendekatan Manajemen Asuhan Kebidanan yang terdiri dari 7 langkah Varney.Dimulai dari langkah pertama, peneliti melakukan pengkajian data dasar dimulai dari data subjektif yang terdiri dari alasan utama ibu datang ke fasilitas kesehatan dan beberapa riwayat. Riwayat yang dibutuhkan diantaranya riwayat keluhan utama, riwayat menstruasi, riwayat kehamilan dan nifas, riwayat $\mathrm{KB}$ yang dapat berupa informasi jenis kontrasepsi apa yang digunakan, apakah ibu pernah mengganti kontrasepsi lain, berapa lama penggunaannya, keluhan pada saat ikut $\mathrm{KB}$, alasan berhenti KB. Di samping itu dibutuhkan pula riwayat kesehatan sekarang dan yang lalu, riwayat penyakit keluarga, riwayat sosial ekonomi, psikososial, dan spiritual, serta riwayat kebutuhan dasar ibu.Selain itu, data objektif pun termasuk data pendukung dalam asuhan kebidanan pada akseptor KB suntik 3 bulan dengan kenaikan berat badan. Data objektif dapat berupa hasil pemeriksaan umum ibu, pemeriksaan tanda-tanda vital, pemeriksaan fisik (head to toe). Terakhir yaitu pemeriksaan penunjang yang dapat digunakan untuk mengetahui kondisi klien yang terdiri dari pemeriksaan laboratorium dan pemeriksaan tes kehamilan.

Pada langkah kedua, peneliti mengidentifikasi diagnosa atau masalah aktual. Pada kasus akseptor KB suntik 3 bulan dengan kenaikan berat badan diagnosis ditegakkan dengan mengidentifikasi adanya data subjektif dan data objektif seperti pada langkah 1.Pada langkah ketiga, peneliti mengidentifikasi diagnosa atau masalah potensial. Pada kasus akseptor KB suntik 3 bulan dengan kenaikan berat badan diagnosa potensial yang kemungkinan terjadi pada kasus akseptor KB suntik 3 bulan dengan kenaikan berat badan adalah Drop Out pada ibu yang sudah merasa cemas dengan peningkatan berat badannya.

Pada langkah keempat, peneliti mengidentifikasi perlunya tindakan segera oleh bidan atau dokter. Pada kasus peningkatan berat badan tindakan antisipasi atau tindakan segera yang harus dilakukan yaitu melakukan pemantauan berat badan, menganjurkan untuk diet rendah kalori, dan olahraga yang teratur (Koes Irianto,2012).Jika terdapat gangguan emosional dapat diberikan konseling keIslaman dan sedapat mungkin melibatkan suami dan anggota keluarga lain. 
Pada langkah kelima, peneliti merencanakan rencana asuhan. Adapun perencanaan asuhan yang diberikan pada akseptor suntik 3 bulan yaitu 2 cara yaitu secara Konseling Informasi Edukasi (KIE) dengan menjelaskan bahwa keluhan yang dirasakan merupakan penyesuain diri dan hanya bersifat sementara dan individu. Secara tindakan medis dapat dilakukan dengan memberikan beberapa tablet suflas ferosus pada akseptor dengan keluhan gangguan menstruasi (Firdayanti, 2012:106-107). Memberikan obat analgesik berupa antalgin, paracetamol, dan asam mefenamet pada akseptor dengan keluhan sakit kepala/pusing (Firdayanti, 2012:109-110).

Pada langkah keenam, peneliti mengimplementasikan rencana asuhan yang telah disusun.Pelaksanaan asuhan kebidanan pada akseptor KB suntik 3 bulan sesuai dengan pelaksanaan yang di laksanakan pada langkah V. Pada langkah ketujuh, evaluasi dari hasil asuhan yang telah diberikan kepada ibu.Evaluasi asuhan kebidanan pada akseptor KB suntik 3 bulan adalah akseptor bersedia melakukan diet rendah kalori dan olahraga yang teratur (Koes Irianto, 2012). Pada tahap terakhir ini dilakukan pemantauan setiap sebulan sekali untuk mengkaji serta menanyakan keadaan umum dan TTV, menimbang berat badan, riwayat menstruasi, serta keluhan lain yang dirasakan oleh klien. Ibu dan suami/anggota keluarga lain mengerti anjuran yang diberikan untuk tetap sabar dan berpiran positif untuk perbaikan kondisi ibu

\section{PEMBAHASAN}

Berdasarkan hasil pengkajian pada ibu didapatkan hasil anamnesis yang menunjukkan bahwa diagnosis Ny"F” PIIA0, Akseptor lama KB suntik DMPA dengan peningkatan berat badan.Antisipasi terjadi Drop Out. Hasil yang diperoleh dari kasus ibu yaitu pada langkah pertama, ibu mengutarakan semua keluhan yang dialaminya dan tidak mengalami hambatan dalam proses pengkajian. Ibu menjadi akseptor KB sudah 2 tahun sejak tahun 2016, pada kartu akseptor ibu, tercantum bahwa ibu memakai suntik Depo Progestin, ibu tidak pernah meggunakan alat kontrasepsi lain selain KB suntik 3 bulan. Dalam penggunaan jangka panjang DMPA (hingga dua tahun) turut memicu terjadinya peningkatan berat badan, kanker, kekeringan pada vagina, gangguan emosi, dan jerawat karena penggunaan hormonal yang lama dapat mengacaukan keseimbangan hormon estrogen dan progesteron dalam tubuh 
sehingga mengakibatkan terjadi perubahan sel yang normal menjadi tidak normal (Saifuddin, 2006).

Pada langkah kedua, Penerepan tinjauan pustaka dan studi kasus Ny "F" secara garis besar tampak ada persamaan dalam diagnosa aktual yaitu $\mathrm{Ny}$ "F" ingin memakai KB suntik 3 bulan untuk menjarangkan kehamilannya dan telah membicarakan kepada suami dan keluarga untuk keinginannya ber-KB. Keadaan umum baik, kesadaran composmentis, TTV dalam batas normal, Berat badan sebelum memakai KB suntik 3 bulan yaitu $50 \mathrm{~kg}$ dan Berat badan sekarang $57 \mathrm{~kg}$, pemeriksaan fisik dan laboratorium normal sehingga diagnosa yang ditegakkan yaitu Ny "F" dengan akseptor suntik 3 bulan dengan peningkatan berat badan.

Pada langkah ketiga, Peningkatan berat badan merupakan hal yang tidak perlu dicemaskan bagi aksepor KB suntik depo progestin karena hal tersebut tidak membahayakan kesehatan dan bersifat sementara. Ketika suntikan di hentikan maka kesuburan akan kembali secara berangsur-angsur. Pada langkah keempat, untuk menanggani akseptor KB suntik 3 bulan.Tidak ada data yang memberikan indikasi adanya tindakan segera dimana harus menyelamatkan jiwa klien, berupa kolaborasi dengan tenaga kesehatan yang lebih profesional sesuai dengan keadaan yang dialami oleh klien ataupun konsultasi dengan dokter.

Pada langkah kelima, tidak terjadi hambatan dalam pemberian informasi kepada pasien bahwa keluhan yang dirasakan merupakan penyesuain diri dan hanya bersifat sementara dan individu. Secara tindakan medis dapat dilakukan dengan memberikan beberapa tablet suflas ferosus pada akseptor dengan keluhan gangguan menstruasi (Firdayanti, 2012:106-107). Memberikan obat analgesik berupa antalgin, paracetamol, dan asam mefenamet pada akseptor dengan keluhan sakit kepala/pusing (Firdayanti, 2012:109-110).

Pada langkah keenam, Tindakan asuhan kebidanan berdasarkan dengan perencanaan asuhan kebidanan yang telah dibuat dilaksanakan seluruhnya dengan baik sehingga penulis tidak menemukan hambatan yang berarti karena adanya kerja sama dan penerimaan yang baik dari ibu dan keluarga serta dukungan, bimbingan dan arahan pembimbing dari lahan praktek. Pada langkah ketujuh, Evaluasi asuhan Ibu mengerti dengan semua penjelasan yang diberikan,Ibu mengerti dengan efek samping dari suntikan DMPA $150 \mathrm{mg}$ dan ibu masih ingin menjadi akseptor suntikan DMPA. Tanda-tanda vital ibu dalam batas normal dan berat 
badan ibu sudah turun $(2 \mathrm{~kg})$ setelah melakukan diet rendah kalori dan olahraga secara teratur.

\section{KESIMPULAN DAN SARAN}

\section{A. KESIMPULAN}

Setelah mempelajari teori, konsep dan prinsip-prinsip serta tinjauan pustaka dari hasil pengkajian Manajemen Asuhan keluarga berencana pada Ny "F" Akseptor suntik DMPA dengan peningkatan berat badan di Puskesmas Bara-baraya Makassar tanggal 07 Juli 2018 s/d 04 agustus 2018, maka dapat ditarik kesimpulan sebagi berikut:

1. Telah dilakukan pengkajian sehingga ditemukan data dasar yang dilakukan dengan cara melakukan anamnesis dan pemeriksaan fisik pada ibu. Data subjektif ibu mengeluh nafsu makan bertambah sehingga mengganggu aktivitas sehari-hari selama menggunakan KB suntik 3 bulan. Data objektif pada kartu akseptor ibu, tercantum bahwa ibu memakai suntikan 3 bulan dan hasil dari pemeriksaan fisik didapatkan BB ibu sebelum KB $50 \mathrm{~kg}$ dan BB sekarang $57 \mathrm{~kg}$. ibu mengalami kenaikan berat badan sebanyak $7 \mathrm{~kg}$.

2. Telah dirumuskan diagnosa/masalah actual pada Ny "F" di puskesmas bara-baraya makassar didapatkan bahwa sejak menggunakan suntikan depo progestin mengalami peningkatan berat badan.

3. Telah dirumuskan diagnosa/masalah potensial pada Ny " $F$ " dengan peningkatan berat badan di puskesmas bara-baraya makassar, yaitu dapat terjadi Drop Out. Namun, pada kasus ini diagnosa potensial tersebut tidak terjadi karena telah diberikan asuhan dan pemantauan yang sesuai, sehingga kondisi ibu bisa membaik.

4. Tindakan segera tidak dilakukan pada Ny "F" karena tidak ada data yang menunjang untuk dilakukan tindakan segera atau kolaborasi.

5. Telah dilaksana rencana asuahan atau intervensi pada $\mathrm{Ny}$ "F" yaitu menganjurkan pada ibu untuk diet rendah kalori dan melakukan olahraga secara rutin, mengobservasi tanda-tanda vital (TTV), serta memantau berat badan ibu.

6. Telah dilaksanakan asuhan atau implementasi pada $\mathrm{Ny}$ " $\mathrm{F}$ " dengan peningkatan berat badan di puskesmas bara-baraya makassar sesuai dengan rencana asuhan yang 
telah disusun seperti makan makanan yang banyak mengandung serat, mengkonsumsi buah-buahan dan melakukan olahraga secara teratur.

7. Telah dilakukan evaluasi terhadap hasil asuhan yang telah dilakukan pada Ny "F" dengan peningkatan berat badan di puskesmas bara-baraya makassar, yaitu berat badan ibu sudah turun ( $2 \mathrm{~kg}$ ), setelah melakukan diet rendah kalori, dan olahraga secara teratur, sehingga ibu tetap menjadi akseptor KB suntik DMPA.

8. Telah dilakukan penerapan nilai-nilai keIslaman dalam manajemen asuhan kebidanan keluarga berencana.

9. Telah dilakukan diskusi kesenjangan antara teori tentang suntikan DMPA

10. dengan efek samping peningkatan berat badan di puskesmas bara-baraya makassar dan didapatkan tidak ada kesenjangan antara teori tentang suntikan DMPA dengan efek samping peningkatan berat badan

\section{B. SARAN}

\section{Untuk Pemerintah}

Penulisan berharap agar Karya Tulis Ilmiah ini dapat sebagai salah satu sumber informasi bagi penentu kebijakan dan pelaksanaan nprogram, baik di Departemen Kesehatan Makassar maupun pihak puskesmas makassar dalam menyusun perencanaan pelaksanaan dan evaluasi program $\mathrm{KB}$

2. Untuk Peneliti selanjutnya

Penulis berharap agar Karya Tulis Ilmiah ini dapat sebagai sumber informasi dan memperkaya khasanah ilmu pengetahuan dan bahan acuan bagi penulis selanjutnya.

\section{Untuk Institusi}

Untuk mendapatkan hasil yang diinginkan perlu kiranya pembelajaran tentang penerapan manajemen kebidanan dalam pemecahan masalah lebih ditingkatkan dan dikembangkan mengingat proses tersebut sangat bermanfaat dalam membina tenaga bidan guna menciptakan sumber daya manusia yang berpotensi dan profesional.

4. Untuk Penulis

Diharapkan agar penulis semakin meningkatkan wawasan keilmuan dan pengalaman yang dimiliki agar semakin mahir dalam menangani kasus kebidanan, termasuk pada kasus KB suntik DMPA dengan peningkatan berat badan. 


\section{DAFTAR PUSTAKA}

Badan Kependudukan dan Keluarga Berencana Nasional.Buku Panduan Praktis Pelayanan Kontrasepsi Edisi Ketiga. Jakarta: Bina Pustaka Sarwono Prawirohardjo. 2011: 37-50

Badan Pusat Statistika. Data Pengguna KB Aktif Di Makassar Tahun 2015, (2016). Https://Sulsel.Bps.Go.Id/ (Di akses tanggal 18 maret 2018)

Berenson AB, Rahman M. Changes In Weight, Total Fat, Percent Body Fat, And Central-ToPeripheral Fat Ratio Associated With Injectable And Oral Contraceptive Use. American Journal Of Obstetrics And Gynecology. 2009: 329e1-E8.

Dewi, Paradian. Susilani, Amalina. Siswatibudi, Harpeni. Rata-Rata Kenaikan Berat Badan Antara Pemakaian Kb Suntik Kombinasi Dengan Dmpa Di Rumah Bersalin Amanda Sleman Tahun 2014-2015. (2016) :35-49.

Firdayanti.Unmeet Need For Family Planning Kebutuhan Keluarga Berencana(KB) Yang Tidak Terpenuhi. Makassar, (2012).

Hartanto H. Keluarga Berencana Dan Kesehatan Reproduksi. Jakarta: Pustaka Sinar harapan, (2010).

Kementerian Kesehatan RI. Profil Kesehatan Indonesia Tahun 2016. Jakarta: Kementrian Kesehatan Indonesia, 2017.

Http://Www.Depkes.Go.Id/Resources/Download/Pusdatin/ProfilKesehatnIndonesia/Profil-Kesehatan-Indonesia-2016.Pdf (Di akses tanggal 18 maret 2018)

Koes, Irianto. Keluarga Berencana Untuk Paramedis Dan Nonmedis. Bandung: Yrama Widya, (2012).

Maryam, Siti, Analisis Persepsi Ibu Tentang Program Keluarga Berencana(KB) Dengan Penggunaan Kontrasepsi di Desa Sumberdadi Kecamatan Sumbergempol Kabupaten Tulungagung Tahun 2014, (2014). Jurnal Universitas Tulungagung :66

Population Reference Bureau. World Population Data Sheetwith A Special Focus On Women's Empowerment. (2015). Http://Www.Prb.Org/Pdf15/2015-World-PopulationData-Sheet Eng.Pdf (Di akses tanggal 18 maret 2018).

Pratiwi, D dkk. Hubungan Antara Penggunaan Kontrasepsi Hormonal Suntik DMPA Dengan Peningkatan Berat Badan Di Puskesmas Lapai Kota Padang.(2014). Artikel Penelitian. 365-366

Saifuddin, dkk.Buku Panduan Praktis Pelayanan Kontrasepsi. Jakarta, (2006). 